\title{
Low density lipoprotein size in relation to carotid intima-media thickness in coronary artery disease
}

\author{
Alabakovska $\mathrm{SB}^{1}$, Tosheska $\mathrm{KN}^{1}$, Spiroski $\mathrm{MZ}^{2}$, Krstevska $\mathrm{MA}^{1}$, Jovanova $\mathrm{S}^{3}$, Labudovic $\mathrm{DD}^{1}$ \\ Department of Medical and Experimental Biochemistry, University "Ss. Cyril and Methodius", Faculty of Medicine, Skopje, \\ Macedonia. salabakovska@yahoo.com
}

\begin{abstract}
Objective: With increasing interest in the role of non-traditional lipid risk factors in coronary artery disease, we undertook this study to relate LDL subclass size and carotid intima-media thickness of the common carotid artery in coronary artery disease patients.

Methods: The study was conducted in 106 patients during their first visit (study group I) and after 12 months (study group II). Intima-media thickness of the common carotid artery was determined using B-mode ultrasound. Separation of LDL subclasses was preformed by 3-31\% polyacrylamide gradient gel electrophoresis.

Results: $\mathrm{LDL}_{3}$ was the dominant subclass in both study groups, but there was statistically significant difference in the distribution of dominant LDL subclasses $(p<0.01)$. The mean carotid intima- media thickness was significantly increased $(p<0.001)$ in coronary artery disease patients after 12 months period. There was significant negative correlation between intima-media thickness and LDL size in both study groups $(p<0.05)$. Intima-media thickness was not significantly correlated with plasma lipid concentrations. Multiple regression analyses show that strongest independent predictor of the intima-media thickness variation was diastolic blood pressure, followed by LDL size and age, and accounted for $29 \%$ of the observed variability in intima-media thickness. Conclusion: LDL particle size is independently associated with carotid intima-media thickness in coronary artery disease patients with normal levels of traditional lipid risk. These results imply that small, dense LDL subclasses are an important indicator for assessing atherosclerosis and its progression (Tab. 4, Ref. 39). Full Text in PDF www.elis.sk.

Key words: LDL size, gradient gel electrophoresis, intima-media thickness, CAD.
\end{abstract}

It is well established that elevated circulating concentrations of cholesterol-rich, low-density lipoproteins (LDL) represent a major risk factor for the premature development of coronary artery disease (1). The LDL fractions have been shown to be heterogeneous in size, density, electric charge, and lipid and apolipoprotein composition (2-6). Analysis of LDL size distribution in normal subject's plasma as well as in dyslipidemic subjects' plasma have revealed that LDL subclasses can be distributed either as monodisperse or polydisperse populations of particles (7-9). It has been shown that small, dense LDL (LDLs) has less affinity to the LDL receptor and therefore has prolonged residence in plasma. They penetrate the arterial wall easily and bind to intimal proteoglycans, undergo oxidative modification which increases their atherogenicity which is considered as an initial step in the atherosclerosis development (10).

\footnotetext{
${ }^{1}$ Department of Medical and Experimental Biochemistry, University "Ss. Cyril and Methodius", Faculty of Medicine, Skopje, Macedonia, ${ }^{2}$ Department of Immunobiology and Human Genetics, University "Ss. Cyril and Methodius, Faculty of Medicine, Skopje, Macedonia, and ${ }^{3}$ University Clinic of Cardiology, Faculty of Medicine, Skopje, Macedonia

Address for correspondence: S. Alabakovska, MD, PhD, Institute of Medical and Experimental Biochemistry, Faculty of Medicine, University "Ss. Cyril and Methodius-Skopje, 50 Divizija no. 6, 1000 Skopje, Macedonia. Phone: +389.2.3217303, Fax: +389.2.3230431
}

Acknowledgement: This work was supported by The Ministry of Science of R.Macedonia, research grant no. 086405; 2009.
Several clinical studies indicate that small LDL size is associated with an increased risk of coronary artery disease (CAD) (1-8). The Adult Treatment Panel (ATP) III has defined emerging risk factors for $\mathrm{CAD}$, including small, dense low-density lipoprotein (LDLs) (11). LDLs particles are present in families with premature CAD and hyperapobetalipoproteinemia, familial combined hyperlipidemia, familial dyslipidemic hypertension, and metabolic syndrome (12-17). Small, dense LDLs are often accompanied by increased triglycerides (TGs) and low high-density lipoproteins (HDL) (18).

A number of methods have been developed to separate LDL subclasses. Nondenaturing polyacrylamide gradient gel electrophoresis is widely used in clinical studies (2-8). The advantage of this method is the possibility to separate up to 7 subclasses within LDL fraction, according to particle size, and is easy to perform.

Evaluation of carotid intima- media thickness (IMT) using ultrasonogaphy is a validated quantitative method for assessing the presence and severity of atherosclerosis. IMT is increased in groups of patients with several cardiovascular risk factors (advanced age, hypertension, smoking, and male gender $(19,20)$. It has been proved that carotid IMT is an independent risk factor for myocardial infarction and stroke, and predicts the progression of $\operatorname{CAD}(21,22)$.

Carotid atherosclerosis has been associated with high triglyceride levels and low HDL cholesterol, known as "atherogenic lipid profile" $(23,24)$. 
Recently, it has been shown that small low-density lipoprotein and LDL particle size are associated with carotid IMT independent of total cholesterol or LDL cholesterol $(25,26)$.

In this study we investigated the relationship of LDL size and other risk factors with intima- media thickness (IMT) of the common carotid artery (CCA) in CAD patients with clinically apparent atherosclerosis at their first visit and 12 months after.

\section{Material and methods}

\section{Subjects and blood samples collection}

Study group I. One hundred and five patients ( 75 men and 30 women, aged 36 to 74 years) with a history of coronary artery disease were recruited at the time of their first visit at the University Cardiology Clinic, Medical Faculty, Skopje.

The diagnosis of CAD was based on the subjects medical history, clinical signs and symptoms, characteristic electrocardiogram changes, increased concentrations of cardiac enzymes and echocardiography assessment of left ventricular systolic and diastolic function. Hypertension was defined as systolic blood pressure $\geq 140 \mathrm{mmHg}$, diastolic blood pressure $\geq 90 \mathrm{mmHg}$, antihypertensive medications, or any combination of these. Individuals with diabetes mellitus, renal diseases, neoplastic disorders, and those treated with lipid-lowering drugs were excluded.

Study group II. Ninety five participants from study group I (68 men and 27 women, aged 41 to 74 years) were analyzed 12 months after their first visit of the Clinic.

The height and weight of each patient was used to calculate body mass index (BMI; $\mathrm{kg} / \mathrm{m}^{2}$ ). The study was performed according to the Helsinki declaration and was approved by the Ethics Committee of the Macedonian Medical Chamber. All subjects signed inform consent forms prior to examination.

\section{Sample preparation}

Venous blood for the analysis was obtained after a 12 hour overnight fast and collected into $\mathrm{K}_{3}$ EDTA containing tubes. After centrifugation at $3000 \mathrm{rpm}$ for 10 minutes, plasma samples were stored at $+4{ }^{\circ} \mathrm{C}$ within 48 hours. One portion of each sample for LDL subclass separation was stored at $-80^{\circ} \mathrm{C}$ until analysis within 2 months.

\section{Lipid and apoprotein measurements}

All lipid measurements were performed in fresh plasma samples, within 48 hours, kept at $+4{ }^{\circ} \mathrm{C}$. Plasma total cholesterol and triglyceride concentrations were examined using enzymatic methods (Randox, Crumlin, UK). Determination of plasma HDL cholesterol concentrations with dextran sulfate-magnesium precipitation was followed by enzymatic determination of cholesterol. The Friedewald formula was used to calculate LDL cholesterol concentrations (27). ApoA-1, ApoB and Lp(a) concentrations were measured by the immunonephelometry method (DADE Behring, Marburg, Germany).

\section{Non-denaturing polyacrylamide gradient gel electrophoresis}

Non-denaturing polyacrylamide 3-31\% gradient gel electrophoresis (PAGE) was performed to separate LDL subclasses and estimates their size. Since sources of specialized Pharmacia GE2/4 electrophoresis chambers and commercial gels have become uncertain, we used an alternative, Mini-Protean II Electrophoresis Apparatus (BioRad 165-2941, Hercules, CA,USA). Therefore, a new casting protocol was developed and glass cassettes fitting the BioRad electrophoresis chamber were made in our laboratory. The gradient gel characteristics and all details of the method have been presented in our previous publication (28). This new gel format allowed LDL and HDL subclasses separation on the same gel and thus duplication of work was avoided.

Plasma samples and human standard were prestained for 18 hours with Sudan Black B for analyses of cholesterol-stained lipoproteins. Ten samples were loaded to each gel. Human plasma standard, high molecular weight protein standard (HMW; 170445-02, Pharmacia Biotech, Uppsala, Sweden) and carboxilated polystyrene microspheres (beads; Duke Scientific, Palo Alto, CA) were loaded to calibrate for particle size. Beads were prestained with Sudan Black B, six hours before loading, and were loaded in the same line as HMW standard, 2 hours after beginning of electrophoresis to avoid mixing. HMW protein standard was stained after separation with Coomassie brilliant blue G-250. The gels were sealed in plastic bags and could be stored for several years with no loss of stain.

Lipoprotein profiles were analyzed using a laser densitometer at $632 \mathrm{~nm}$ with Image Master Software (version 1,0; 1993; Pharmacia). LDL peak particle sizes were calculated from the calibration curve based on the inverse relationship between the log of the known sizes of the standards on the $y$-axis and their migration distances from the start of the gel (Rf) on the x-axis. LDL peak particle sizes in the plasma sample absorbance profiles were calculated using Gels Scan software (56-1131-38, Pharmacia). LDL subclasses were classified as phenotype A (diameter $<25.5 \mathrm{~nm}$ ) and phenotype $\mathrm{B}$ (diameter $>25.5 \mathrm{~nm}$ ).

\section{Measurement of intima- media thickness}

The ultrasonographic scanning of the common carotid arteries (CCA) was performed using high resolution B-mode ultrasonography (SSA-770A; Toshiba, Tokyo, Japan) with a linear array probe (7.5 MHz), according to a standardized protocol. The IMT was measured manually by using a special vernier caliper after taking a picture. The far walls of right and left common carotid artery were scanned. IMT was evaluated by measuring the linear distance, perpendicular to the luminal axis, between 2 points defined by the ultrasonic interface, $1 \mathrm{~cm}$ distal to the carotid bifurcation. CCA IMT was calculated as the mean of the right and left CCA.

\section{Statistical analysis}

The data are presented as mean \pm standard deviation (SD). Comparison of mean LDL particle sizes, age, plasma lipid and apoprotein concentrations between groups was performed with the two-sample unpaired Student's t-test. The differences in LDL subclass distribution between two groups were evaluated with $\chi^{2}$ -test. Pearson correlation and multiple regression analysis were performed to investigate association between IMT and other clinical and laboratory parameters. The value of $\mathrm{p}<0.05$ was considered 
Tab. 1. Clinical and laboratory variables of CAD patients (study group I and study group II).

\begin{tabular}{llll}
\hline Parameter & CAD $(\mathrm{I})$ & $\mathrm{CAD}(\mathrm{II})$ & $\mathrm{p}$ \\
\hline BMI $\left(\mathrm{kg} / \mathrm{m}^{2}\right)$ & $27.5 \pm 3.6$ & $27.9 \pm 3.5$ & $>0.05$ \\
Total cholesterol $(\mathrm{mmol} / \mathrm{L})$ & $4.58 \pm 1.35$ & $4.76 \pm 1.37$ & $<0.005$ \\
HDL cholesterol $(\mathrm{mmol} / \mathrm{L})$ & $1.026 \pm 0.02$ & $1.03 \pm 0.02$ & $>0.05$ \\
LDL cholesterol $(\mathrm{mmol} / \mathrm{L})$ & $2.89 \pm 1.34$ & $3.03 \pm 1.28$ & $<0.001$ \\
Triglycerides $(\mathrm{mmol} / \mathrm{L})$ & $1.50 \pm 0.01$ & $1.6 \pm 0.3$ & $<0.005$ \\
ApoB $(\mathrm{g} / \mathrm{L})$ & $1.05 \pm 0.60$ & $1.15 \pm 0.50$ & $>0.05$ \\
ApoA-1 $(\mathrm{g} / \mathrm{L})$ & $1.31 \pm 0.05$ & $1.32 \pm 0.25$ & $>0.05$ \\
Lp $(\mathrm{a})(\mathrm{g} / \mathrm{L})$ & $0.3 \pm 0.02$ & $0.33 \pm 0.19$ & $>0.05$ \\
LDL diameter. size $(\mathrm{nm})$ & $25.71 \pm 0.57$ & $25.02 \pm 0.86$ & $>0.05$ \\
HDL diameter. size $(\mathrm{nm})$ & $9.49 \pm 0.82$ & $9.34 \pm 0.74$ & $>0.05$ \\
IMT $(\mathrm{mm})$ & $0.83 \pm 0.02$ & $0.91 \pm 0.026$ & $<0.001$ \\
Diastolic BP $(\mathrm{mm} \mathrm{Hg})$ & $80.9 \pm 12$ & $82 \pm 11$ & $>0.05$ \\
Systolic BP $(\mathrm{mm} \mathrm{Hg})$ & $145 \pm 17$ & $140 \pm 16$ & $>0.05$ \\
\hline
\end{tabular}

Data are presented as mean \pm S.D.

Tab. 2. Distribution of dominant LDL subclasses in patients with CAD (\%).

\begin{tabular}{|c|c|c|c|c|c|}
\hline $\begin{array}{l}\text { Predominant } \\
\text { LDL subclass }\end{array}$ & Phenotype & $\begin{array}{l}(\%) \text { I } \\
\text { pregled }\end{array}$ & $\begin{array}{c}\text { Phenotype } \\
(\%)\end{array}$ & $(\%)$ II & $\begin{array}{c}\text { Phenotype } \\
(\%)\end{array}$ \\
\hline$\overline{\text { LDL } 1}$ & & 2.2 & & 0 & \\
\hline LDL 2 & A & 37.6 & 39.8 & 24 & 24 \\
\hline LDL 3 & & 59 & & 66 & \\
\hline LDL 4 & B & 2.2 & 61.2 & 10 & 76 \\
\hline
\end{tabular}

significant difference for all analyses in the study. All statistical analyses were done using STATWIN software (version 5.0 A, Statsoft Inc. 1984-95; Tulsa, OK 74104, USA).

\section{Results}

Clinical and laboratory variables of participants in study group I and study group II are shown in Table 1.

There were no statistical differences in plasma HDL cholesterol, ApoA, ApoB, Lp(a), BMI, systolic and diastolic blood pressure between the groups.

Patients from study group II had significantly higher mean total cholesterol $(p<0.005)$, LDL cholesterol $(p<0.001)$ and triglycerides $(p<0.005)$ compared to study group I.

Although LDL particle size was not statistically different between two study groups, LDL size was slightly decreased $(25.71 \pm 0.57 \mathrm{~nm}$ vs $25.02 \pm 0.86$; N.S.) in CAD patients after 12 months period.

The mean IMT in all participants was $0.89 \pm 0.13 \mathrm{~mm}$ and was significantly increased 12 months after the first measurement $(0.91 \pm 0.026 \mathrm{~mm} ; \mathrm{p}<0.001)$.

Table 2 displays the LDL subclasses distribution in two study groups. In most patients from study group I (61.2\%), atherogenic phenotype B was observed due to the presence of smaller LDL subclasses as dominant subclass (LDL3 and LDL4). In $39.8 \%$ of the patients LDL1 and LDL2 subclasses were dominant and they belonged to phenotype A. In study group II, $76 \%$ of the patients belonged to the phenotype B, while $24 \%$ of the patients had phenotype A.

LDL3 was the dominant subclass in both study groups, but there was statistically significant difference in the distribution of dominant LDL subclasses with shift towards smaller subclasses in study group II $\left(\chi^{2}=4.79 ; p<0.01\right)$.

Univariate linear regression analysis was used to determine the association of clinical and laboratory variables to CCAIMT (Tab. 3).

Correlation between the IMT and respective variables in patients from study group I ( $\mathrm{n}=105)$ and study group II $(\mathrm{n}=95)$.

Of the laboratory variables, LDL size of the dominant subclass showed the strongest negative correlation with CCA IMT in both study groups. In contrast, other lipid and apoprotein plasma concentrations were not significantly associated with CCA IMT in both study groups, although plasma lipid concentrations were increased in study group II. Major LDL size was strongly inversely related to the IMT of the CCA, indicating that a predominance of small LDL particles is associated with an increased IMT.

Of the clinical parameters, diastolic blood pressure $(\mathrm{r}=0.5$, $\mathrm{p}<0.05 ; \mathrm{r}=0.48, \mathrm{p}<0.05$, for both study group respectively); and systolic blood pressure $(r=0.49, \mathrm{p}<0.05 ; \mathrm{r}=0.51, \mathrm{p}<0.05$, for both study groups respectively) were also significantly related to the CCA IMT. Age was also significantly correlated with IMT in both study groups $(r=0.26, p<0.05 ; \mathrm{r}=0.25, \mathrm{p}<0.05$ for both study groups respectively).

Multiple regression analysis was performed to identify independent determinants of CCA IMT. Variables that were significant in univariate analysis were used as independent variables in multiple regression analysis (Tab. 4).

Age, systolic, diastolic blood pressure and LDL size accounted for $29 \%$ of the observed variability in IMT. Other variables were not independent factors for IMT. In both study groups, multiple regression analysis show that strongest independent predictor of the IMT variation was diastolic blood pressure $(0.322, \mathrm{p}=0.016 ; 0.324$,

Tab. 3. Correlation between the IMT and respective variables in patients from study group I $(n=105)$ and study group II $(n=95)$.

\begin{tabular}{llllll}
\hline Parameter & \multicolumn{2}{c}{ CAD (I) } & & \multicolumn{2}{c}{ CAD (II) } \\
\cline { 2 - 3 } \cline { 5 - 6 } & $\mathrm{r}$ & $\mathrm{p}$ & $\mathrm{r}$ & $\mathrm{p}$ \\
\hline Age & 0.26 & $\mathrm{p}<0.05$ & $\mathrm{r}=0.25$ & $\mathrm{p}<0.05$ \\
BMI & $\mathrm{r}=0.02$ & $\mathrm{p}>0.05$ & $\mathrm{r}=0.01$ & $\mathrm{p}>0.05$ \\
Total cholesterol & $\mathrm{r}=0.05$ & $\mathrm{p}>0.05$ & $\mathrm{r}=0.18$ & $\mathrm{p}>0.05$ \\
HDL cholesterol & $\mathrm{r}=-0.16$ & $\mathrm{p}>0.05$ & & $\mathrm{r}=-0.07$ & $\mathrm{p}>0.05$ \\
LDL cholesterol & $\mathrm{r}=0.09$ & $\mathrm{p}>0.05$ & & $\mathrm{r}=0.17$ & $\mathrm{p}>0.05$ \\
Triglycerides & $\mathrm{r}=0.01$ & $\mathrm{p}>0.05$ & $\mathrm{r}=0.15$ & $\mathrm{p}>0.05$ \\
ApoB & $\mathrm{r}=0.02$ & $\mathrm{p}>0.05$ & $\mathrm{r}=0.12$ & $\mathrm{p}>0.05$ \\
ApoA-1 & $\mathrm{r}=0.06$ & $\mathrm{p}>0.05$ & & $\mathrm{r}=0.10$ & $\mathrm{p}>0.05$ \\
Lp(a) & $\mathrm{r}=0.10$ & $\mathrm{p}>0.05$ & & $\mathrm{r}=0.13$ & $\mathrm{p}>0.05$ \\
LDL size & $\mathrm{r}=-0.51$ & $\mathrm{p}<0.05$ & $\mathrm{r}=-0.56$ & $\mathrm{p}<0.05$ \\
HDL size & $\mathrm{r}=0.05$ & $\mathrm{p}>0.05$ & $\mathrm{r}=0.03$ & $\mathrm{p}>0.05$ \\
Diastolic pressure & $\mathrm{r}=0.5$ & $\mathrm{p}>0.05$ & $\mathrm{r}=0.48$ & $\mathrm{p}>0.05$ \\
Systolic pressure & $\mathrm{r}=0.49$ & $\mathrm{p}>0.05$ & $\mathrm{r}=0.51$ & $\mathrm{p}>0.05$ \\
\hline
\end{tabular}

Tab. 4. Determinants of carotid artery IMT in patients with coronary artery disease by multiple linear regression analysis.

\begin{tabular}{llllll}
\hline Parameter & \multicolumn{2}{l}{ CAD (I) } & & \multicolumn{2}{l}{ CAD (II) } \\
\cline { 2 - 3 } \cline { 5 - 6 } & beta & p-level & & beta & $\mathrm{p}$-level \\
\hline Age & 0.192 & 0.037 & 0.206 & $\mathrm{p}=0.035$ \\
LDL size & 0.26 & 0.04 & 0.269 & $\mathrm{p}=0.039$ \\
Diastolic pressure & 0.322 & 0.016 & & 0.324 & $\mathrm{p}=0.018$ \\
Systolic pressure & 0.237 & 0.067 & 0.204 & 0.072 \\
\hline
\end{tabular}


$\mathrm{p}=0.018$, respectively), followed by LDL size $(0.260, \mathrm{p}=0.04$; $0.269, \mathrm{p}=0.039$, respectively) and age $(0.192, \mathrm{p}=0.037,0.206$, $\mathrm{p}=0.035$, respectively).

\section{Discussion}

A number of studies have examined the relationship between LDL heterogeneity and CAD. In the first population-based casecontrol study (29) a threefold increased risk of myocardial infarction was found in subjects with a predominance of small dense LDL particles (phenotype B). The cross-sectional studies consistently suggest an association between small dense LDL particles and CAD. A plasma concentration of small dense LDL, (above 100 $\mathrm{mg} / \mathrm{dL}$ ) was associated with a 4.5 -fold increased risk of CAD (30).

We used high resolution polyacrylamide gel electrophoresis to measure LDL size of the dominant subclass in CAD patients. LDL3 was dominant subclass in both study groups, but there was statistically significant difference in the distribution of dominant LDL subclasses with shift towards smaller subclasses in CAD patients after 12 months period $\left(\chi^{2}=4.79 ; \mathrm{p}<0.01\right)$. Although LDL particle size was not statistically different between two study groups, mean LDL size was slightly decreased in CAD patients after 12 months period.

Our results were in agreement with other case-control studies reporting an increased prevalence of small LDL particles (phenotype B) in patients with coronary artery disease (26, 29, 30,3 1), and confirmed the association of small LDL particles and coronary artery disease.

An increased IMT is considered a reliable marker of early atherosclerosis (25). Increased carotid IMT and its progression are associated with cardiovascular risk factors (32). Therefore, we measured IMT using high resolution B-mode ultrasonography to estimate atherosclerosis and its progression in CAD patents at their first visit and after 12 months. The mean IMT in all participants was $0.89 \pm 0.13 \mathrm{~mm}$ and was significantly increased 12 months after the first measurement $(0.91 \pm 0.026 \mathrm{~mm} ; \mathrm{p}<0.001)$.

In our study, we also demonstrated that LDL size is strongly associated with IMT of the carotid arteries and multivariate analysis revealed that LDL size was the second strongest predictor of IMT, after diastolic blood pressure. The association is shown to be independent of plasma LDL concentration and together with diastolic blood pressure and age accounted for $29 \%$ of the observed variability in IMT. This association was observed in CAD patients at their first visit (study group I), and after 12 months (study group II) which indicates that LDL size is a good marker of atherosclerosis progression.

In line with our results, LDL particle size has been reported to be associated with carotid IMT in middle-aged subjects in the study of Skoglund et al (30) and Hulthe et al $(31,33)$.

It has been demonstrated that small LDLs are independently related to common carotid artery $\operatorname{IMT}(30,32,34)$. In the study of Liu et al (24), LDL particle size correlated significantly with mean IMT even after adjustment for age, BMI and sex. Results from their multivariate analysis demonstrate that LDL particle size is independently associated with mean IMT.
Several pathophysiological mechanisms for the increased atherogenecity of small LDL have been suggested. Compared with larger and more buoyant LDL particles small LDL more readily infiltrate the arterial wall, bind more tightly to arterial wall proteoglycans and are more susceptible to oxidative modification (35, 36,3 7).

Furthermore, small dense LDL particles have a prolonged plasma residence time most probably due to a decreased affinity for the LDL receptor and in effect an extended opportunity to exert atherogenic effect (36).

Although the metabolic origin of small dense LDL is not fully understood, the distribution of LDL particle size in human plasma is believed to be the result of the coordinated actions of hepatic and endothelial lipases as well as mediators of neutral lipid exchange $(38,39)$.

In conclusion, our results suggest that LDL particle size is significantly associated with carotid IMT in CAD patients independent of traditional lipid and established risk factors. Small dense LDL particles play an important role in causing vascular change, leading to atherosclerosis. Our results indicate that the evaluation of LDL particle size distribution with a high-resolution polyacrylamide gel electrophoresis may be a valuable approach to estimate individual cardiovascular risk and predictor of atherosclerosis progression in patients with established atherosclerosis as well as in asymptomatic individuals. Such follow-up may facilitate the directed development of preventive strategies.

\section{References}

1. Grundy MS. Role of low-density lipoproteins in atherogenesis and development of coronary heart disease. Clin Chem 1995; 41 (1): 139-146.

2. Krauss MR. Low-density lipoprotein subclasses and risk of coronary artery disease. Curr Opin Lipid. 1991; 2: 248-252

3. Krauss MR, Bruke JD. Identification of multiple subclasses of plasma low density lipoproteins in normal humans. J Lipid Res 1982; 23: 97-104.

4. Krauss RM. Heterogeneity of plasma low density lipoproteins and atherosclerosis risk. Curr Opin Lipidol. 1994; 5: 339-349.

5. Packard CJ, Shepherd J. Lipoprotein heterogeneity and apolipoprotein B metabolism. Atheroscler Thromb Vasc Biol 1997; 17 (12): 3542-3556.

6. Chapman MJ, Laplaud PM, Luc G, Forgez P, Bruckert E, Goulinet S, Lagrange D. Further resolution of the low density lipoprotein spectrum in normal human plasma: physicochemical characteristics of discrete subspecies separated by density gradient ultracentrifugation. J Lipid Res 1988; 29 (4): 442-458.

7. Saheki S, Hitsumoto Y, Bando S, Murase M, Takeuchi N, Uchida K. Compositions of very low density lipoprotein subfractions from patients with polydisperse low density lipoproteins. Clin Chim Acta 1995; 238 (1): 43-57.

8. Alabakovska S, Labudovic D, Tosheska K, Todorova B. Low density lipoprotein particle size phenotyping in healthy persons and patients with myocardial infarction. Croat Med J 2002; 43 (3): 290-295.

9. Lagrost L, Gandijani H, Athias A, Guyard-Dangremont V, Lallemant C, Gambert P. Influence of plasma cholesteryl ester transfer activity on the LDL and HDL distribution profiles in normolipidemic subjects. Atheroscler Thromb 1993; 13 (6): 815-825. 
10. Deckelebaum RJ, Galeano NF. Small dense low density lipoprotein: formation and potential mechanisms for atherogenecity. I J Med Sci 1996; 32 (6): 464-468.

11. Liao Y, Know S, Shaughnessy S, Wallace P, Huto A, Jenkins AJ, Klein RL, Garvey WT. Critical evaluation of adult treatment panel III criteria in identifying insulin resistance with dyslipidemia. Diabetes Care 2004; 27 (4): 978-983.

12. Musunuru K. Atherogenic dyslipidemia: cardiovascular risk and dietary intervention. Lipids 2010; 45 (10): 907-914.

13. López-Ruiz A, Jarabo MM, Martínez-Triguero ML, MoralesSuárez-Varela M, Solá E, Banuls C, Casado M, Hernández-Mijares A. Small and dense LDL in familial combined hyperlipidemia and N291S polymorphism of the lipoprotein lipase gene. Lipids Health Dis 2009; 8: 12.

14. Koba S, Yokota Y, Hirano T, Ito Y, Ban Y, Tsunoda F, Sato T, Shoji M, Suzuki H, Geshi E, Kobayashi Y, Katagiri T. Small LDL-cholesterol is superior to LDL-cholesterol for determining severe coronary atherosclerosis. J Atheroscler Thromb 2008; 15 (5): 250-260.

15. Williams K, Tchernof A, Hunt KJ, Wagenknecht LE, Haffner SM, Sniderman AD. Diabetes, abdominal adiposity, and atherogenic dyslipoproteinemia in women compared with men. Diabetes 2008; 57 (12): 3289-3296.

16. Magkos F, Mohammed BS, Mittendorfer B. Effect of obesity on the plasma lipoprotein subclass profile in normoglycemic and normolipidemic men and women. Int J Obes (Lond) 2008; 32 (11): 1655-1664.

17. Juo SH, Beaty TH, Kwiterovich PO Jr. Etiologic heterogeneity of hyperapobetalipoproteinemia (hyperapoB). Results from segregation analysis in families with premature coronary artery disease. Atheroscler Thromb Vasc Biol 1997; 17 (11): 2729-2736.

18. Choi CU Seo HS, Lee EM, Shin SY, Choi UJ, Na JO, Lim HE, Kim JW, Kim EJ, Rha SW, Park CG, Oh DJ. Statins do not decrease small, dense low-density lipoprotein. Tex Heart Inst J 2010; 37 (4): 421-428.

19. Dogan S, Duivenvoorden R, Grobbee DE, Kastelein JJ, Shear CL, Evans GW, Visseren FL, Bots ML; Radiance 1 and 2 Study Groups. Completeness of carotid intima media thickness measurements depends on body composition: the RADIANCE 1 and 2 trials. J Atheroscler Thromb 2010; 17 (5): 526-535.

20. Chambless LE, Folsom AR, Clegg LX, Sharrett AR, Shahar E, Nieto FJ, Rosamond WD, Evans G. Carotid wall thickness is predictive of incident clinical stroke: the Atherosclerosis Risk in Communities (ARIC) study. Am J Epidemiol 2000; 151 (5): 478-487.

21. Lorenz MW, Markus HS, Bots ML, Rosvall M, Sitzer M. Prediction of clinical cardiovascular events with carotid intima-media thickness: a systematic review and meta-analysis. Circulation 2007; 115 (4): 459-467.

22. Poredos P. Intima-media thickness: indicator of cardiovascular risk and measure of the extent of atherosclerosis. Vasc Med 2004; 9 (1): 46-54.

23. Baldassarre D, Amato M, Bondioli A, Sirtori CR, Tremoli E. Carotid artery intima-media thickness measured by ultrasonography in normal clinical practice correlates well with atherosclerosis risk factors. Stroke 2000; 31 (10): 2426-2430

24. Lui ML, Ylitalo K, Nuotio I, Salonen R, Salonen JT, Taskinen MR. Association between carotid intima-media thickness and low-density lipoprotein size and susceptibility of low-density lipoprotein to oxidation in asymptomatic members of familial combined hyperlipidemia families. Stroke 2002; 33 (5): 1255-1260.

25. Sekikawa A, Ueshima H, Sutton-Tyrrell K, Kadowaki T, El-Saed A, Okamura T, Takamiya T, Ueno Y, Evans RW, Nakamura Y, Edmundowicz D, Kashiwagi A, Maegawa H, Kuller LH. Intima-media thickness of the carotid artery and the distribution of lipoprotein subclasses in men aged 40 to 49 years between whites in the United States and the Japanese in Japan for the ERA JUMP study. Metabolism 2008; 57 (2): 177-182.

26. Landray MJ, Sagar G, Muskin J, Murray S, Holder RL, Lip GY. Association of atherogenic low-density lipoprotein subfractions with carotid atherosclerosis. QJM 1998; 91 (5): 345-351.

27. Friedewald WT, Levy RI, Fredrickson DS. Estimation of the concentration of low-density lipoprotein cholesterol in plasma, without use of the preparative ultracentrifuge. Clin Chem 1972; 18: 499-502.

28. Alabakovska SB, Todorova BB, Labudovic DD, Tosheska KN. Gradient gel electrophoretic separation of LDL and HDL subclasses on BioRad Mini Protean II and size phenotyping in healthy Macedonians. Clin Chim Acta 2002; 317 (1-2): 119-123.

29. Austin AM, King M, Vranizan MK, Krauss MR. Atherogenic lipoprotein phenotype. A proposed genetic marker for coronary heart disese risk. Circulation 1990; 82: 495-506.

30. Skoglund-Andersson C, Tang R, Bond MG, de Faire U, Hamsten A, Karpe F. LDL particle size distribution is associated with carotid intimamedia thickness in healthy 50-year-old men. Arterioscler Thromb Vasc Biol 1999; 19 (10): 2422-2430.

31. Hulthe J, Bokemark L, Wikstrand J, Fagerberg B. The metabolic syndrome, LDL particle size, and atherosclerosis: the Atherosclerosis and Insulin Resistance (AIR) study. Arterioscler Thromb Vasc Biol 2000; 20 (9): 2140-2147.

32. Mora $\mathbf{S}$ et al. LDL particles subclasses, LDL particle size and cerotid atherosclerosis in the Multi-Ethnic Study of atherosclerosis (MESA). Atherosclerosis 2007; 192: 211-217.

33. Hulthe J, Wiklund O, Bondjers G, Wikstrand J. LDL particle size in relation to intima-media thickness and plaque occurrence in the carotid and femoral arteries in patients with hypercholesterolaemia. J Intern Med 2000; 248 (1): 42-52.

34. Lyons $\mathbf{T J}$ et al. Nuclear magnetic resonance-determined lipoprotein subclass profile in the DCCT/EDIC chort: associations with carotid intimamedia thickness. Diabet Med 2006; 23: 955-966.

35. Galeano NF, Al-Haideri M, Keyserman F, Rumsey SC, Deckelbaum RJ. Small dense low density lipoprotein has increased affinity for LDL receptor-independent cell surface binding sites: a potential mechanism for increased atherogenicity. J Lipid Res 1998; 39 (6): 1263-1273.

36. Camejo G, Lopez A, Lopez F, Quinónez J. Interaction of low density lipoproteins with arterial proteoglycans. The role of charge and sialic acid content. Atherosclerosis 1985; 55 (1): 93-105.

37. Tribble DL, Rizzo M, Chait A, Lewis DM, Blanche PJ, Krauss RM. Enhanced oxidative susceptibility and reduced antioxidant content of metabolic precursors of small, dense low-density lipoproteins. Am J Med. 2001; 10 (2): 103-110.

38. Tan CE, Foster L, Caslake MJ, Bedford D, Watson TD, McConnell M, Packard CJ, Shepherd J. Relations between plasma lipids and postheparin plasma lipases and VLDL and LDL subfraction patterns in normolipemic men and women. Arterioscler Thromb Vasc Biol 1995; 15: 1839-1848.

39. Guerin M, Le Goff W, Lassel TS, van Tol A, Steiner G, Chapman MJ. Atherogenic role of elevated CE transfer from HDL to VLDL(1) and dense LDL in type 2 diabetes: impact of the degree of triglyceridemia. Arterioscler Thromb Vasc Biol 2001; 21: 282-288.

Received December 21, 2010. Accepted December 18, 2011. 